\section{Kidney \\ Blood Pressure Research}

\title{
Genotype-Phenotype Analysis in Pediatric Patients with Distal Renal Tubular Acidosis
}

\author{
Eujin Park ${ }^{\mathrm{a}}$ Myung Hyun Cho ${ }^{\mathrm{a}}$ Hye Sun Hyun ${ }^{\mathrm{a}}$ Jae Il Shin ${ }^{\mathrm{b}}$ Joo Hoon Lee \\ Young Seo Park ${ }^{c}$ Hyun Jin Choi ${ }^{a, d}$ Hee Gyung Kang ${ }^{a, e}$ Hae Il Cheonga,d,e \\ aDepartment of Pediatrics, Seoul National University Children's Hospital, Seoul, 'Department of \\ Pediatrics, Severance Children's Hospital, Yonsei University, Seoul, 'Department of Pediatrics, Asan \\ Medical Center, University of Ulsan, Seoul, 'Research Coordination Center for Rare Diseases, Seoul \\ National University Hospital, Seoul, eKidney Research Institute, Medical Research Center, Seoul National \\ University College of Medicine, Seoul, Korea
}

\section{Key Words}

Distal renal tubular acidosis - Mutations - Sensorineural hearing loss • Nephrocalcinosis • Chronic kidney disease $\cdot$ Growth retardation

\begin{abstract}
Background/Aims: Primary distal renal tubular acidosis (dRTA) in children is a rare genetic disorder, and three causative mutated genes have been identified: SLC4A1, ATP6V1B1, and ATP6VOA4. We analyzed the prevalence and phenotypic differences of genetic mutations in children with dRTA. Methods: A total of 17 children with dRTA were enrolled in the study. All patients underwent genetic testing for all three candidate genes. Results: Pathogenic mutations, including six novel mutations, were detected in 15 (88.2\%) patients: dominant SLC4A1 mutations in ten (58.8\%) patients, recessive ATP6VOA4 mutations in three $(17.6 \%)$ patients, and recessive ATP6V1B1 mutations in two (11.8\%) patients. Compared to other patients, patients with SLC4A1 mutations showed an older age of onset (3.7 \pm 2.6 years) and less severe metabolic acidosis at initial presentation. All patients developed nephrocalcinosis, and sensorineural hearing loss was observed in two patients with ATP6V1B1 mutations. Three (17.6\%) patients had decreased renal function (chronic kidney disease stage 2), and five (29.4\%) patients had persistent growth retardation at the last follow-up. Long-term prognosis showed no genotype-phenotype correlation. Conclusions: SLC4A1 is the most common defective gene in Korean children with dRTA. Patients with SLC4A1 mutations show later onset and milder disease severity. Long-term follow-up of hearing ability, renal function, and growth is necessary for patients with dRTA.




\section{Kidney \\ Blood Pressure Research}

Park et al.: Childhood Distal Renal Tubular Acidosis

\section{Introduction}

Distal renal tubular acidosis (dRTA), also referred to as type 1 RTA, is clinically characterized by persistent hyperchloremic metabolic acidosis with normal serum anion gap, hypokalemia, hypercalciuria, and nephrocalcinosis. Metabolic acidosis in this disease is caused by an inability of the $\alpha$-intercalated cells in the collecting duct to secrete $\mathrm{H}^{+}$and to properly acidify urine $[1,2]$. In children, dRTA is almost always observed as a primary entity with underlying genetic causes, while in adults, dRTA frequently develops secondarily as a consequence of other diseases including hypergammaglobulinemia, some autoimmune disorders, chronic liver diseases, and chronic renal allograft rejection [2]. To date, at least three genes are known to cause primary dRTA: ATP6V1B1, ATP6VOA4, and SLC4A1 [1, 3]. ATP6V1B1 and ATP6VOA4 encode the B1 and A4 subunits of the apical $\mathrm{H}^{+}$-ATPase pump in $\alpha$-intercalated cells, respectively, and mutations in these genes cause autosomal recessive (AR) forms of dRTA with or without sensorineural hearing loss (SNHL) [4, 5]. SLC4A1 encodes the basolateral anion $\left(\mathrm{Cl}^{-} / \mathrm{HCO}_{3}^{-}\right)$exchanger 1 (AE1) [6, 2]. The majority of SLC4A1 mutations have been reported in association with the autosomal dominant (AD) form of dRTA [6]. However, AR dRTA with or without accompanying hemolytic anemia caused by SLC4A1 mutations has also been reported, predominantly from tropical Southeast Asia and other tropical regions [7, 8].

Children with primary dRTA typically present with growth failure, polyuria, hypercalciuria, medullary nephrocalcinosis, nephrolithiasis, and hypokalemia. The progression of nephrocalcinosis may lead to the development of chronic kidney disease (CKD). Therapeutic correction of the metabolic acidosis by adequate alkali supplementation, if started early in life, may enable catch-up growth, arrest of nephrocalcinosis, and preserve renal function $[2,9]$.

Several genotype-phenotype correlation studies in patients with primary dRTA have been reported, although the results from these studies vary [10-15].

In this study, we analyzed the genotype-phenotype correlation in 17 Korean pediatric patients with dRTA and compared the results with those reported by other studies.

\section{Materials and Methods}

\section{Study population}

A total of 17 pediatric patients who were admitted to or referred for genetic testing to Seoul National University Children's Hospital with a clinical diagnosis of dRTA from 2002 to 2015 were included in this study. All patients were Korean and none of them were from a consanguineous background. The clinical diagnosis of dRTA was based on laboratory testing of hyperchloremic metabolic acidosis with a normal plasma anion gap, normal renal function, and inappropriately high urinary $\mathrm{pH}$ on repeated sampling. None of the patients had so called "incomplete dRTA", which refers to patients with no overt metabolic acidosis at baseline but with urinary acidifying defect (urinary $\mathrm{pH}>5.3$ ) following the administration of an acid load. Medical records and biochemical data were retrospectively reviewed. The estimated glomerular filtration rate (eGFR) was measured using the bedside Schwartz formula [16].

\section{Mutational screening}

Mutational screening was performed for all patients. Genomic DNA was extracted from nucleated cells in the peripheral blood using a commercially available kit (QIAamp DNA Blood Mini Kit; QIAGEN, Hilden, Germany), and all coding exons with flanking introns of SLC4A1, ATP6V1B1, and ATP6VOA4 were amplified using PCR followed by direct sequencing. In addition, we also screened $C A 2$, which encodes the cytosolic carbonic anhydrase II and causes combined distal and proximal RTA with osteopetrosis [17]. 


\section{Kidney Blood Pressure Research}

Park et al.: Childhood Distal Renal Tubular Acidosis

\section{Statistical analyses}

Qualitative data were described as frequencies whereas quantitative data were reported as the means \pm standard deviations. The Chi-square test or Fisher's exact test was used, as appropriate, to compare proportions between groups. Quantitative variables were compared using the Mann-Whitney $U$ test. All statistical analyses were performed using IBM SPSS Statistics for Windows, version 22 (IBM Corp., Armonk, N.Y., USA). A $P$ value $<0.05$ was considered statistically significant.

\section{Ethical Approval}

This study was conducted in accordance with the 1964 Declaration of Helsinki and was approved by the Seoul National University Hospital's Institutional Review Board. Informed consent was obtained from all individual participants included in this study.

\section{Results}

\section{Clinical presentations}

Of the 17 pediatric patients in this study population, 11 were male and 6 were female. The mean age at onset was $2.3 \pm 2.6$ (range, 0.1-8.0) years, and the mean age at the last follow-up was $12.1 \pm 8.9$ (range, $0.3-32.3$ ) years. Three patients had a family history of dRTA. One patient with ATP6VOA4 mutations had an affected sibling. One patient with a SLC4A1 mutation and another patient without any genetic mutation had an affected mother. All patients were born after a normal full-term pregnancy, and their birth weights ranged from 2.92 to $4.6 \mathrm{~kg}$, except for one patient without any mutation who was prematurely born at $35^{+3}$ weeks of gestation. Vomiting $(n=5)$ and urinary tract infection $(n=5)$ were the two most common presenting symptoms of dRTA, followed by short stature/rickets $(\mathrm{n}=$ $4)$, failure to thrive $(n=3)$, and incidentally detected nephrocalcinosis $(n=1)$. Of the two patients without a genetic mutation, nephrocalcinosis was detected in one patient on fetal ultrasonography, and his metabolic acidosis became evident at the age of two weeks. The other patient presented with rickets at the age of 1.7 years, and his mother was affected by dRTA and rickets. At initial presentation, 11 patients showed hypokalemia (serum $\mathrm{K}^{+}<3.5$ $\mathrm{mEq} / \mathrm{L}$ ) at the initial presentation: six patients with SLC4A1 mutations, two patients with ATP6V0A4 mutations, two patients with ATP6V1B1 mutations, and one patient without any genetic mutation. In addition, one patient with an ATP6V1B1 mutation had hyponatremia (serum $\mathrm{Na}^{+} 129 \mathrm{mEq} / \mathrm{L}$ ). None of the patients with $S L C 4 A 1$ mutation had red blood cell abnormalities. SNHL was noted in two patients with ATP6V V1B1 mutations. Medullary nephrocalcinosis was detected in all patients at the time of diagnosis $(\mathrm{n}=14)$ or during follow-up ( $\mathrm{n}=3)$. In one patient with an SLC4A1 mutation, nephrocalcinosis was detected on the initial renal ultrasonography at the time of diagnosis, but it disappeared on a followup ultrasonography taken after 2 years of alkali treatment. All patients were treated with oral potassium citrate with or without sodium bicarbonate. At the last follow-up, three (17.6\%) patients showed mild renal impairment (CKD stage 2): one patient with an SLC4A1 mutation (eGFR $83 \mathrm{~mL} / \mathrm{min} / 1.73 \mathrm{~m}^{2}$ ), one patient with ATP6V1B1 mutations (eGFR 79 $\mathrm{mL} / \mathrm{min} / 1.73 \mathrm{~m}^{2}$ ), and one patient without genetic mutations (eGFR $72 \mathrm{~mL} / \mathrm{min} / 1.73 \mathrm{~m}^{2}$ ). At the last follow-up, five patients had a height equal to or below a -2 standard deviation score: three patients with SLC4A1 mutations, one patient with ATP6VOA4 mutations, and one patient without genetic mutations. However, two of the patients with SLC4A1 mutations and persistent growth failure were followed up with for short periods only.

\section{Mutational studies}

Mutational tests revealed pathogenic mutations in 15 of the 17 patients (88.3\%), including SLC4A1 mutations for AD dRTA in 10 patients (58.8\%), ATP6V0A4 mutations in 3 patients (17.6\%), and ATP6V1B1 mutations in 2 patients $(11.8 \%)$. In the remaining two patients, no pathogenic mutation was detected in any of the four genes. Six of the mutations 


\section{Kidney \\ Blood Pressure Research}

Park et al.: Childhood Distal Renal Tubular Acidosis

Table 1. Genotypes of patients with distal renal tubular acidosis. ${ }^{a}$ novel mutations

\begin{tabular}{|c|c|c|c|}
\hline Patients & Mutated gene & Mutation 1 & Mutation 2 \\
\hline 1 & ATP6V1B1 & c.228G>T, p.R76S & c.368G>T, p.G123V \\
\hline 2 & ATP6V1B1 & c.1356delT, p.F452Lfs & homozygote \\
\hline 3 & ATP6VOA4 & c.1558_1561delTTTGinsAC, p.F520Tfs*3a & c. 2257 C>T, p.Q753* \\
\hline 4 & ATP6V0A4 & c. $1029+5 \mathrm{G}>\mathrm{A}$ in intron $10^{\mathrm{a}}$ & c.1181C $>$ A, p.A394Da \\
\hline 5 & ATP6V0A4 & c.2261T>G, p.L754R & c.1890G >A, p.A630T \\
\hline 6 & $S L C 4 A 1$ & c.1766G>A, p.R589H & \\
\hline 7 & SLC4A1 & c.2381A>G, p.Y794Ca & \\
\hline 8 & SLC4A1 & c. $1765 C>T$, p.R589C & \\
\hline 9 & SLC4A1 & c.1766G>A, p.R589H & \\
\hline 10 & SLC4A1 & c.1766G>A, p.R589H & \\
\hline 11 & SLC4A1 & c. $1765 \mathrm{C}>\mathrm{T}$, p.R589C & \\
\hline 12 & SLC4A1 & c.1765C>T, p.R589C & \\
\hline 13 & SLC4A1 & c.1765C >T, p.R589C & \\
\hline 14 & SLC4A1 & c. $2704 \mathrm{G}>$ A. p.D902Na & \\
\hline 15 & SLC4A1 & c. $1765 \mathrm{C}>\mathrm{T}, \mathrm{p} . \mathrm{R} 589 \mathrm{C}$ & \\
\hline
\end{tabular}

Table 2. Comparison of clinical findings between patients with SLC4A1 mutations (Group 1) and patients with ATP6V0A4 or ATP6V1B1 mutations (Group 2). ${ }^{a}$ estimated glomerular filtration rate calculated using the bedside Schwartz formula, ${ }^{b}$ patients with a height equal to or below -2 standard deviation score

\begin{tabular}{|c|c|c|c|}
\hline Variables & Group $1(n=10)$ & Group $2(n=5)$ & $\mathrm{P}$ value \\
\hline Onset age (years) & $3.7 \pm 2.6(0.6-8.0)$ & $0.2 \pm 0.1(0.1-0.3)$ & 0.002 \\
\hline Gender (M:F) & $7: 3$ & $2: 3$ & 0.329 \\
\hline Current age (years) & $14.0 \pm 9.6$ & $9.4 \pm 7.5$ & 0.159 \\
\hline \multicolumn{4}{|l|}{ Initial laboratory data } \\
\hline Serum sodium (mEq/L) & $137 \pm 2$ & $138 \pm 10$ & 0.575 \\
\hline Serum potassium (mEq/L) & $3.2 \pm 0.6$ & $2.9 \pm 0.6$ & 0.387 \\
\hline Serum chloride (mmol/L) & $111 \pm 6$ & $115 \pm 13$ & 0.759 \\
\hline Serum bicarbonate $(\mathrm{mmol} / \mathrm{L})$ & $15 \pm 3$ & $10 \pm 4$ & 0.013 \\
\hline Blood pH & $7.30 \pm 0.06$ & $7.20 \pm 0.06$ & 0.042 \\
\hline Serum anion gap (mmol/L) & $11 \pm 4$ & $13 \pm 5$ & 0.667 \\
\hline \multicolumn{4}{|l|}{ Current laboratory data } \\
\hline Serum sodium (mEq/L) & $140 \pm 2$ & $141 \pm 3$ & 0.135 \\
\hline Serum potassium $(\mathrm{mEq} / \mathrm{L})$ & $3.9 \pm 0.4$ & $4.4 \pm 0.6$ & 0.210 \\
\hline Serum chloride (mmol/L) & $107 \pm 3$ & $108 \pm 4$ & 0.355 \\
\hline Serum bicarbonate $(\mathrm{mmol} / \mathrm{L})$ & $23 \pm 4$ & $24 \pm 4$ & 0.711 \\
\hline $\mathrm{eGFR}^{\mathrm{a}}\left(\mathrm{mL} / \mathrm{min} / 1.73 \mathrm{~m}^{2}\right)$ & $107 \pm 45$ & $112 \pm 36$ & 0.854 \\
\hline Patients with eGFR $\geq 90$ & $9(90 \%)$ & $4(80 \%)$ & 1.000 \\
\hline Patients with eGFR 60-90 & $1(10 \%)$ & $1(20 \%)$ & 1.000 \\
\hline Patients with growth failure & $3(30 \%)$ & $1(20 \%)$ & 1.000 \\
\hline
\end{tabular}

were novel, and two common mutations in SLC4A1 were observed: p.R589C was detected in five patients and p.R589H was detected in three patients (Table 1). Co-segregation of the biallelic mutations with the phenotype of the family members, including both parents, was confirmed in all five patients with ATP6V0A4 or ATP6V1B1 mutations. Among the 10 patients with SLC4A1 mutations, 8 had a de novo mutation and 1 had a mutation inherited from the mother. In the remaining patient, parental samples were unavailable.

\section{Genotype-phenotype correlations}

Patients with SLC4A1 mutations (Group 1) had an older age at onset (3.7 \pm 2.6 years; range, $0.6-8.0)$ compared to other patients $(0.4 \pm 0.6$ years; range, $0-1.7)$ or patients with ATP6VOA4 or ATP6V1B1 mutations (Group 2; $0.2 \pm 0.1$ years; range, 0.1-0.3). At the initial presentation, patients with SLC4A1 mutations showed less severe acidosis (higher serum bicarbonate and blood pH levels) than other patients. Group 1 patients had higher initial serum potassium levels than Group 2 patients but without statistical significance (Table 2). Clinical features at initial presentation in patients with ATP6V1B1 mutations and patients 


\section{Kidney Blood Pressure Research}

with ATP6VOA4 mutations were similar, although the number of patients in both groups was very small. At the last follow-up, no statistically significant difference was observed in the renal outcome or the rate of failure to catch-up growth according to the genotypes of the patients (Table 2).

\section{Discussion}

Several comprehensive genotype-phenotype correlation studies of patients with dRTA have been published worldwide $[10,13,15]$. In this Korean cohort study of pediatric patients with dRTA, the most distinctive finding compared to other studies was the high incidence (58.8\%) of patients with SLC4A1 mutations (Table 3). In one previous study [10] including eight Asian patients, only one Asian patient had compound heterozygous SLC4A1 mutations. All of the 10 patients with SLC4A1 mutations in our study had the AD form of dRTA, which is different from the AR dRTA that is prevalent in Southeast Asian countries [7, 8]. In a small-scale study in China [12], which is a neighboring Far East country, none of the four index patients with dRTA had SLC4A1 mutations. However, a study from Japan [14], another neighboring country, screened only ATP6V1B1 and ATP6VOA4 and showed that five of the nine index patients had no mutations in either of the genes and that at least some of these five patients are likely to have SLC4A1 mutations.

In the current study, we found six novel mutations: four in ATP6VOA4 [c.1558_1561delTTTGinsAC (p.F520Tfs*3), c.1181C>A (p.A394D), c.2261T>G (p.L754R), and c.1029+5G>A in intron 10] and two in SLC4A1 [c.2381A>G (p.Y794C) and c.2704G>A (p.D902N)]. Although we did not perform any functional studies, all four novel missense mutations were predicted to be pathogenic by web-based programs, including PolyPhen-2 (http://genetics.bwh.harvard.edu/pph2/), SIFT (http://sift.jcvi.org/), and Mutation Taster (http://www.mutationtaster.org/). The allele frequency of the c.1029+5G $>A$ variation (rs147476317) in ATP6V0A4 is reported to be 0.00002514 on the ExAc Browser (http://exac. broadinstitute.org/). Although we did not perform any functional studies for this variation, web-based programs, including NetGene2 (http://www.cbs.dtu.dk/services/NetGene2/), BDGP (http://www.fruitfly.org/) and GENSCAN 1.0 (http://genes.mit.edu/GENSCAN.html) predicted this variation to cause abnormal splicing.

In this study, patients with SLC4A1 mutations presented with milder metabolic acidosis with an older onset age than patients with ATP6V1B1 or ATP6V0A4 mutations. However, the clinical courses and the long-term prognosis showed no difference between the two groups. These findings were consistent with those of previously reported studies $[10,13,15]$.

The p.R589H in SLC4A1, the most common mutation causing AD dRTA, was shown to exhibit only mild reduction in anion-exchange activity [18]. One study [19] showed that retention of heterologous AE1 p.R589H in the endoplasmic reticulum of polarized Madin-Darby canine kidney cells, along with co-retention of co-expressed wild-type AE1, suggesting dominant negative trafficking defects. However, a recent study [20] with an Ae1

Table 3. Underlying genetic defect in patients with distal renal tubular acidosis compared to that in other studies. apatients who have a heterozygous mutation(s) in one or two (digenic) of the genes

\begin{tabular}{|c|c|c|c|c|c|c|}
\hline \multirow{2}{*}{$\begin{array}{l}\text { Studies } \\
\text { (No. of index cases) }\end{array}$} & \multirow{2}{*}{$\begin{array}{l}\text { Origin of } \\
\text { patients }\end{array}$} & \multicolumn{4}{|c|}{ Mutated genes } & \multirow{2}{*}{ No mutation } \\
\hline & & ATP6V1B1 & ATP6V0A4 & SLC4A1 & Heterozygotesa & \\
\hline Palazzo et al. $(n=89)[10]$ & Italian 70 & $25(28 \%)$ & $30(38 \%)$ & $9(10 \%)$ & $7(8 \%)$ & $18(20 \%)$ \\
\hline Besouw et al. $(n=23)[11]$ & $\begin{array}{c}\text { Asian 8, } \\
\text { Caucasian } 7\end{array}$ & $6(26 \%)$ & $9(39 \%)$ & $4(17 \%)$ & $1(4 \%)$ & $3(13 \%)$ \\
\hline Gómez et al. $(n=10)$ [12] & Caucasian 7 & $1(10 \%)$ & $4(40 \%)$ & $3(30 \%)$ & $1(10 \%)$ & $1(10 \%)$ \\
\hline Elhayek et al. $(n=20)[13]$ & Tunisian 20 & $13(65 \%)$ & $5(25 \%)$ & 0 & $2(10 \%)$ & 0 \\
\hline Gao et al. $(n=4)[14]$ & Chinese 4 & $2(50 \%)$ & $2(50 \%)$ & 0 & 0 & 0 \\
\hline Miura et al. $(n=9)[15]$ & Japanese 9 & $2(22 \%)$ & $2(22 \%)$ & Not tested & 0 & $5(56 \%)$ \\
\hline This study $(\mathrm{n}=17)$ & Korean 17 & $2(12 \%)$ & $3(18 \%)$ & $10(59 \%)$ & 0 & $2(12 \%)$ \\
\hline
\end{tabular}




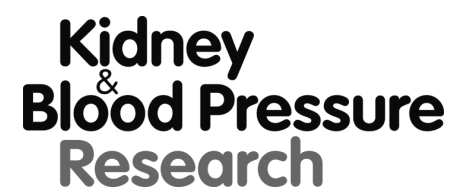

\begin{tabular}{l|l}
\hline Kidney Blood Press Res 2018;43:513-521 \\
\hline DOI: 10.1159/000488698 & $\begin{array}{l}\text { (c) 2018 The Author(s). Published by S. Karger AG, Basel } \\
\text { www.karger.com/kbr }\end{array}$ \\
Published online: 6 April, 2018 &
\end{tabular}

Park et al.: Childhood Distal Renal Tubular Acidosis

p.R607H knock-in mouse model (which corresponds to human AE1 p.R589H) showed that both heterozygous and homozygous knock-in mice exhibited incomplete dRTA (less severe in heterozygotes than in homozygotes). Interestingly, the targeting of Ae1 p.R607H to the basolateral plasma membrane of the $\alpha$-intercalated cells was normal, as was transport activity in vivo. In addition, impaired targeting of the $\mathrm{H}^{+}$-ATPase and fewer $\alpha$-intercalated cells indicated underlying impaired acid secretion in both heterozygous and homozygous knock-in mice. In the present study, none of the patients, including three patients carrying dominant p.R589H mutations, had incomplete dRTA. In addition, the clinical and laboratory findings of the patients with p.R589H mutations were not significantly different from the patients carrying other SLC4A1 mutations (data not shown).

SNHL is also often associated with dRTA, primarily in patients with ATP6V1B1 or ATP6V0A4 mutations. Previous studies have shown that ATP6V1B1 mutations typically cause dRTA with SNHL, whereas ATP6V0A4 mutations are responsible for dRTA in patients without SNHL or with late-onset hearing loss $[4,5]$. However, this concept was challenged by later studies that demonstrated genetic heterogeneity in dRTA associated with SNHL $[21,22]$. Therefore, it is currently believed that the presence or onset age of SNHL cannot discriminate between ATP6V1B1 and ATP6VOA4 mutations. In a recent large cohort study [15], the frequencies of the accompanying SNHL in patients with ATP6V1B1 and ATP6VOA4 mutations were $92 \%$ and $56.7 \%$, respectively. In addition, SNHL in patients with ATP6V1B1 mutations showed an earlier onset than SNHL in those carrying ATP6VOA4 mutations. However, SNHL in the latter group of patients presented a wider age range of clinical onset of SNHL (range, 2-552 months), encompassing infancy and early childhood. Notably, one patient with a homozygous SLC4A1 mutation in the study had been diagnosed with SNHL at 12 years of age; however, the causal relationship between the genetic defect and the development of SNHL remains unclear. These findings warrant the long-term follow-up of hearing in children with dRTA, normal results in an initial hearing screening, and mutations in any of the genes or in whom no mutation is detected. In our study, SNHL was noted in both patients with ATP6V1B1 mutations only, and no other patient developed SNHL during follow-up.

Medullary nephrocalcinosis is one of the characteristic findings of dRTA. In patients with chronic acidosis, excessive bone mineralization results in hypercalciuria, which, in turn, can result in nephrocalcinosis and/or nephrolithiasis. In our study, all patients had nephrocalcinosis. Interestingly, nephrocalcinosis was detected on fetal ultrasonography in one patient without a genetic mutation, and it disappeared after treatment in another patient with an SLC4A1 mutation.

Some patients with dRTA present hypokalemia and salt-losing nephropathy [2]. Because dRTA is genetically a single-cell disease involving only the $\alpha$-intercalated cells, these symptoms are not explained easily, as they are not directly related to the $\alpha$-intercalated cell functions. Gueutin et al. [23] demonstrated that inactivation of the B1 subunit of the apical $\mathrm{H}^{+}$-ATPase not only affects the $\alpha$-intercalated cells, causing a defect in acid secretion as expected, but also impairs $\mathrm{Na}^{+}$and $\mathrm{Cl}^{-}$reabsorption along the cortical collecting ducts. This impairment occurs by primarily diminishing the function of the $\beta$-intercalated cells and thus, secondarily, affecting the principal cells as well. In addition, defective water and salt reabsorption along the cortical collecting ducts causes hypokalemia associated with dRTA. Therefore, dRTA should be reconsidered as a renal disease involving different renal epithelial cell types. In this present study, 11 patients showed hypokalemia and one of the patients also had hyponatremia at the initial presentation. However, there was no genotype-phenotype correlation in the serum potassium and sodium levels at the initial presentation.

Patients with dRTA may develop CKD during long-term follow-up, which could be explained by the combination of nephrocalcinosis and persistent hypokalemia, leading to progressive tubulointerstitial damage, or by kidney damage following repeated episodes of dehydration and acute kidney injury. A large cohort study showed CKD in 32.3\% of all patients (31.3\% patients with pathogenic mutations) [15], and another study observed CKD in $37.5 \%$ 


\section{Kidney \\ Blood Pressure Research}

of all patients (36.8\% patients with pathogenic mutations) [10]. Most of the patients with CKD in these studies were followed up with for at least 15 years or longer. In our study, CKD was observed in $17.6 \%$ of the total patients (13.3\% of patients with pathogenic mutations). The lower frequency in our study may be attributed to the shorter follow-up period.

Growth failure and/or rickets, resulting from excessive bone mineralization in association with chronic metabolic acidosis, are another characteristic feature of untreated patients with dRTA. However, catch-up growth is observed in most patients after the initiation of alkaline treatment [24]. In a recent study [10], growth retardation with a height below a -2 standard deviation score was found in 12 of the 24 patients at presentation but persisted in only three of these children once alkali treatment was initiated. In our study, at the last follow-up, five patients had persistent growth retardation: three patients with SLC4A1 mutations, one patient with ATP6VOA4 mutations, and one patient without genetic mutations. However, two of the patients with SLC4A1 mutations were followed up for very short periods to evaluate catch-up growth. All patients with persistent growth retardation had normal eGFR, except for one patient without genetic mutations whose current eGFR was $72 \mathrm{~mL} / \mathrm{min} / 1.73 \mathrm{~m}^{2}$.

\section{Conclusion}

In the genotype-phenotype correlation study of 17 Korean pediatric patients with dRTA, we found that 1) SLC4A1 was the most common defective gene, 2) patients with SLC4A1 mutations showed milder metabolic acidosis with older onset age, and 3) there was no genotype-phenotype correlation in the long-term prognosis. Although dRTA is generally accepted as a benign disorder when adequate alkali therapy is initiated early in life, our results suggest that long-term follow-up is necessary to monitoring hearing ability, renal function, and growth.

\section{Acknowledgements}

This study was supported by the Korean Health Technology R\&D Project, Ministry of Health \& Welfare (HI12C0014).

\section{Disclosure Statement}

The authors declare that they have no conflicts of interest.

\section{References}

1 Karet FE: Inherited distal renal tubular acidosis. J Am Soc Nephrol 2002;13:2178-2184.

-2 Soriano JR: Renal tubular acidosis: the clinical entity. J Am Soc Nephrol 2002;13:2160-2170.

-3 Batlle D, Haque SK: Genetic causes and mechanisms of distal renal tubular acidosis. Nephrol Dial Transplant 2012;27:3691-3704.

-4 Karet FE, Finberg KE, Nelson RD, Nayir A, Mocan H, Sanjad SA, Rodriguez-Soriano J, Santos F, Cremers CW, Di Pietro A, Hoffbrand BI, Winiarski J, Bakkaloglu A, Ozen S, Dusunsel R, Goodyer P, Hulton SA, Wu DK, Skvorak AB, Morton CC, et al.: Mutations in the gene encoding B1 subunit of $\mathrm{H}^{+}$-ATPase cause renal tubular acidosis with sensorineural deafness. Nat Genet 1999;21:84-90.

-5 Smith AN, Skaug J, Choate KA, Nayir A, Bakkaloglu A, Ozen S, Hulton SA, Sanjad SA, Al-Sabban EA, Lifton RP, Scherer SW, Karet FE: Mutations in ATP6N1B, encoding a new kidney vacuolar proton pump 116-kD subunit, cause recessive distal renal tubular acidosis with preserved hearing. Nat Genet 2000;26:71-75. 


\section{Kidney \\ Blood Pressure Research}

Park et al.: Childhood Distal Renal Tubular Acidosis

6 Karet FE, Gainza FJ, Györy AZ, Unwin RJ, Wrong O, Tanner MJ, Nayir A, Alpay H, Santos F, Hulton SA, Bakkaloglu A, Ozen S, Cunningham MJ, di Pietro A, Walker WG, Lifton RP: Mutations in the chloridebicarbonate exchanger gene AE1 cause autosomal dominant but not autosomal recessive distal renal tubular acidosis. Proc Natl Acad Sci USA 1998;95:6337-6342.

7 Khositseth S, Bruce LJ, Walsh SB, Bawazir WM, Ogle GD, Unwin RJ, Thong MK, Sinha R, Choo KE, Chartapisak W, Kingwatanakul P, Sumboonnanonda A, Vasuvattakul S, Yenchitsomanus P, Wrong O: Tropical distal renal tubular acidosis: clinical and epidemiological studies in 78 patients. Q J Med 2012;105:861-877.

-8 Tanphaichitr VS, Sumboonnanonda A, Ideguchi H, Shayakul C, Brugnara C, Takao M, Veerakul G, Alper SL: Novel AE1 mutations in recessive distal renal tubular acidosis: loss-of-function is rescued by glycophorin. Am J Clin Invest 1998;102:2173-2179.

9 Caldas A, Broyewr M, Dechaux M, Kleinknecht C: Primary distal tubular acidosis in childhood: Clinical study and long-term follow-up of 28 patients. J Pediatr 1992;121:233-241.

10 Besouw MTP, Bienias M, Walsh P, Kleta R, Van't Hoff WG, Ashton E, Jenkins L, Bockenhauer D: Clinical and molecular aspects of distal renal tubular acidosis in children. Pediatr Nephrol 2017;32:987-996.

11 Elhayek D, Perez de Nanclares G, Chouchane S, Hamami S, Mlika A, Troudi M, Leban N, Ben Romdane W, Gueddiche MN, El Amri F, Mrabet S, Ben Chibani J, Castaño L, Haj Khelil A, Ariceta G: Molecular diagnosis of distal renal tubular acidosis in Tunisian patients: proposed algorithm for Northern Africa populations for the ATP6V1B1, ATP6VOA4 and SCL4A1 genes. BMC Med Genet 2013;14:119.

12 Gao Y, Xu Y, Li Q, Lang Y, Dong Q, Shao L: Mutation analysis and audiologic assessment in six Chinese children with primary distal renal tubular acidosis. Ren Fail 2014;36:1226-1232.

13 Gómez J, Gil-Peña H, Santos F, Coto E, Arango A, Hernandez O, Rodríguez J, Nadal I, Cantos V, Chocrón S, Vergara I, Madrid Á, Vazquez C, González LE, Blanco F: Primary distal renal tubular acidosis: novel findings in patients studied by next-generation sequencing. Pediatr Res 2016;79:496-501.

14 Miura K, Sekine T, Takahashi K, Takita J, Harita Y, Ohki K, Park MJ, Hayashi Y, Tajima A, Ishihara M, Hisano M, Murai M, Igarashi T: Mutational analyses of the ATP6V1B1 and ATP6VOA4 genes in patients with primary distal renal tubular acidosis. Nephrol Dial Transplant 2013;28:2123-2130.

15 Palazzo V, Provenzano A, Becherucci F, Sansavini G, Mazzinghi B, Orlandini V, Giunti L, Roperto RM, Pantaleo M, Artuso R, Andreucci E, Bargiacchi S, Traficante G, Stagi S, Murer L, Benetti E, Emma F, Giordano M, Rivieri F, Colussi G, et al.: The genetic and clinical spectrum of a large cohort of patients with distal renal tubular acidosis. Kidney Int 2016;91:1243-1255.

16 Schwartz GJ, Muñoz A, Schneider MF, Mak RH, Kaskel F, Warady BA, Furth SL: New equations to estimate GFR in children with CKD. J Am Soc Nephrol 2009;20:629-637.

17 Sly WS, Hewett-Emmett D, Whyte MP, Yu YS, Tashian RE: Carbonic anhydrase II deficiency identified as the primary defect in the autosomal recessive syndrome of osteopetrosis with renal tubular acidosis and cerebral calcification. Proc Natl Acad Sci USA 1983;80:2752-2756.

18 Jarolim P, Shayakul C, Prabakaran D, Jiang L, Stuart-Tilley A, Rubin HL, Simova S, Zavadil J, Herrin JT, Brouillette J, Somers MJ, Seemanova E, Brugnara C, Guay-Woodford LM, Alper SL: Autosomal dominant distal renal tubular acidosis is associated in three families with heterozygosity for the R589Hmutation in the AE1 (band 3) $\mathrm{Cl}^{-} / \mathrm{HCO}_{3}{ }^{-}$exchanger. J Biol Chem 1998;273:6380-6388.

19 Cordat E, Kittanakom S, Yenchitsomanus PT, Li J, Du K, Lukacs GL, Reithmeier RA: Dominant and recessive distal renal tubular acidosis mutations of kidney anion exchanger 1 induce distinct trafficking defects in MDCK cells. Traffic 2006; 7:117-128.

20 Mumtaz R, Trepiccione F, Hennings JC, Huebner AK, Serbin B, Picard N, Ullah AKMS, Păunescu TG, Capen DE, Lashhab RM, Mouro-Chanteloup I, Alper SL, Wagner CA, Cordat E, Brown D, Eladari D, Hübner CA: Intercalated Cell Depletion and Vacuolar H+-ATPase Mistargeting in an Ae1 R607H Knockin Model. J Am Soc Nephrol 2017;28:1507-1520.

21 Stover EH, Borthwick KJ, Bavalia C, Eady N, Fritz DM, Rungroj N, Giersch AB, Morton CC, Axon PR, Akil I, Al-Sabban EA, Baguley DM, Bianca S, Bakkaloglu A, Bircan Z, Chauveau D, Clermont MJ, Guala A, Hulton SA, Kroes H, et al.: Novel ATP6V1B1 and ATP6VOA4 mutations in autosomal recessive distal renal tubular acidosis with new evidence for hearing loss. J Med Genet 2002;39:796-803. 


\section{Kidney Blood Pressure Research}

-22 Vargas-Poussou R, Houillier P, Le Pottier N, Strompf L, Loirat C, Baudouin V, Macher MA, Déchaux M, Ulinski T, Nobili F, Eckart P, Novo R, Cailliez M, Salomon R, Nivet H, Cochat P, Tack I, Fargeot A, Bouissou F, Kesler GR, et al.: Genetic investigation of autosomal recessive distal renal tubular acidosis: evidence for early sensorineural hearing loss associated with mutations in the ATP6VOA4 gene. J Am Soc Nephrol 2006;17:1437-1443.

-23 Trepiccione F, Prosperi F, de la Motte LR, Hübner CA, Chambrey R, Eladari D, Capasso G: New findings on the pathogenesis of distal renal tubular acidosis. Kidney Dis (Basel) 2017;3:98-105.

-24 Rodriguez-Soriano J, Vallo A, Castillo G, Oliveros R: Natural history of primary distal renal tubular acidosis treated since infancy. J Pediatr 1982;101:669-676. 